\title{
Sustainability evaluation models for specific countries
}

\author{
Kaite Li \\ (Department of Electrical Engineering, North China Electric Power University, Baoding 071000, \\ China ;)
}

501368027@qq.com

\begin{abstract}
Keywords: sustainable Development Index (SDI) model; economic benefits (EB); environmental pressure (EP); Principal component analysis (PCA)
\end{abstract}

\begin{abstract}
In order to measure the level of sustainability of a country, we have adopted two different kinds of methods to measure it.

In basic model , a indicator of the level of sustainable development is defined. There we use the ratio of a country's social economic benefits and environmental pressure to reflect the sustainable development level of a country. At last we get scores of sustainable development level of these five countries.

Improved model takes the fact that Principal component analysis (PCA) for main factors selection is a relatively strongly subjective model while the basic model is a relatively objective model into consideration. Improved model is the combination of two models. The improved model employs entropy value method to give obtained scores of each model a weight, and then utilizes the linear weighted method to get a comprehensive score to measure a country's level of sustainability. We apply the improved model to 48 countries in order to solve the problem.
\end{abstract}

\section{Introduction}

Recent few decades have witnessed not only the development of the economy and society, but also the increasing damage to the environment. Therefore the definition of "sustained development" has been put forward to do with it.

Sustainable develop mentis a road-map, an action plan, for achieving sustain ability in any activity that uses resources and where immediate and intergenerational replication is demanded. As such, sustainable development is the organizing principle for sustaining finite resources necessary to provide for the needs of future generations of life on the planet. It is a process that envisions a desirable future state for human societies in which living conditions and resource-use continue to meet human needs without undermining the "integrity, stability and beauty" of natural biotic systems.[1]

The United Nations World Commission on Environment and Development [1](WCED) in its 1987 report Our Common Future[2]defines sustainable development: "Development that meets the needs of the present without compromising the ability of future generations to meet their own needs." Under the principles of the United Nations Charter the Millennium Declaration identified principles and treaties on sustainable development, including economic development, social development and environmental protection. Broadly defined, sustainable development is a systems approach to growth and development and to manage natural, produced, and social capital for the welfare of their own and future generations. The term sustainable development as used by the United Nations incorporates both issues associated with land development and broader issues of human development such as education, public health, and standard of living. 


\section{Modeling}

The five countries' scores of four main factors have be given as follows:

\begin{tabular}{|c|c|c|c|c|c|}
\hline & America & China & Canada & Sudan & Haiti \\
\hline Economic scores & 0.8619 & 0.3822 & 0.6127 & 0.0980 & 0.101 \\
\hline Social scores & 0.8275 & 0.7217 & 0.9260 & 0.490 & 0.4776 \\
\hline Envirommental scores & 0.512 & 0.4134 & 0.668 & 0.7806 & 0.7072 \\
\hline comprehensive scores & 0.7463 & 0.4134 & 0.668 & 0.7806 & 0.7072 \\
\hline
\end{tabular}

\subsection{General Assumptions}

2.1.1The data we have collected is enough in quantity, accurate in quality, while the process of quantification includes no mistakes.

2.1.2The factors we overlooked will not make big changes to the results.

2.1.3The sustainability of a country or a policy is only judged by economy, society and environment factors

\subsection{Model Overview}

SDI model is the model that uses sustainable Development Index (SDI) to evaluate the sustainability of a country. After getting the result and analyzing it, we manage to calculate the value of SDI for all the five countries we have mentioned.

Improved model is the combination for Principal component analysis (PCA) for main factors selection and the SDI model. This paper utilizes the Entropy method to obtain the weights of two models. By employing the linear weighted method, this paper gets the final scores of the five countries. After obtaining the scores of the improved model, we get the chart of sustainable development degree evaluation. In model application, we manage to obtain each year's sustainability score for Haiti.

\subsection{The model of sustainable Development Index (SDI) model}

Seeing that systematic social economic benefits (EB) is proportional to the development goals , while the environmental pressure (EP) is inversely proportional to the sustainable demand ,so we can use the systematic social economic benefits as the numerator in a fraction , while let the environmental pressure serve as the denominator .In this way, we manage to create a comprehensive evaluation index that proportional to the sustainable development performance, and we name it sustainable Development Index (SDI. The bigger of the SDI, the higher social economic benefits we get in Unit of environmental pressures and the better sustainability the system gets. The Mathematical expressions of it is :

Among them,

SDI: sustainable Development Index

EP: environmental pressure

$\mathrm{EP}=\mathrm{ELR}+\sum_{\mathrm{i}=1}^{\mathrm{n}}\left(\frac{\mathrm{X}_{\mathrm{i}}-\mathrm{X}_{\mathrm{iv}}}{\mathrm{A}_{\mathrm{i}}}\right)$

$$
\text { SDI }=\frac{\text { EB }}{\mathbf{E P}}
$$

Among them,

ELR: Environment Load Rate

F: Purchased nonrenewable resources input

$\mathrm{N}$ : free nonrenewable resources input

$\mathrm{R}$ : free renewable resources input

R’: Purchased renewable resources input

Ai: The total pollution levels of the pollutant

Xi: ith Pollutant's pollution levels to the environment

Xiv: before system being into operating, the pollution levels of the Pollutant in the surrounding environment

\subsection{Result and analysis}

According to the collected information and data [3]on the issue, we manage to calculate the value of SDI for all the five country we have mentioned, the specific value can be seen as the following chart: 


\begin{tabular}{|c|c|c|c|c|c|}
\hline & America & China & Canada & Sudan & Haiti \\
\hline ELR & 1.763875 & 1.617056 & 1.063003 & 2.896341463 & 9.479167 \\
\hline EI & 2.096875 & 2.386056 & 1.463003 & 3.521341463 & 10.22917 \\
\hline EB & 1.428571 & 1.250000 & 1.333333 & 1.086956522 & 1.075269 \\
\hline EDI & 0.681285 & 0.523877 & 0.811367 & 0.30867683 & 0.205118 \\
\hline
\end{tabular}

From the chart above, we can safely come to the conclusion that America and Canada have a better sustainability relatively; while Sudan and Haiti have a relatively poor sustainability;

\subsection{Improved model}

The method in Principal component analysis (PCA) for main factors selection is a subjective method, it largely depends on artificial judge; The SDI method is an objective method, it all depends on the data. To comprehensively consider the effect of subjective and objective factors, we adopt linear weighted method:

$W 1+W 2=1$

$\mathrm{H}=W 1 \mathrm{H} 1+W 2 \mathrm{H} 2$

Among them, $\mathrm{H} 1$ is the evaluation grade of model of Principal component analysis (PCA) for main factors selection, $\mathrm{H} 2$ is the evaluation grade of SDI method. All of them range from 0 to 1.

To determine the weight $W 1$ and $W 2$, We use the Entropy method to obtain the weight:

$[W 1, W 2]=[0.3579,0.6421]$

In this way, we are able to obtain the scores of the improved model as follows:

\begin{tabular}{|c|c|c|c|c|c|}
\hline & America & Canada & China & Sudan & Haiti \\
\hline Model & 0.6813 & 0.8114 & 0.5288 & 0.3087 & 0.2051 \\
\hline $\begin{array}{c}\text { Improved } \\
\text { model }\end{array}$ & 0.7046 & 0.7722 & 0.5078 & 0.3373 & 0.2657 \\
\hline
\end{tabular}

\subsection{Result and analysis}

According to the chart above ,with the help of our collected data[3] ,we can reasonably come to the chart of sustainable development degree evaluation as follows:

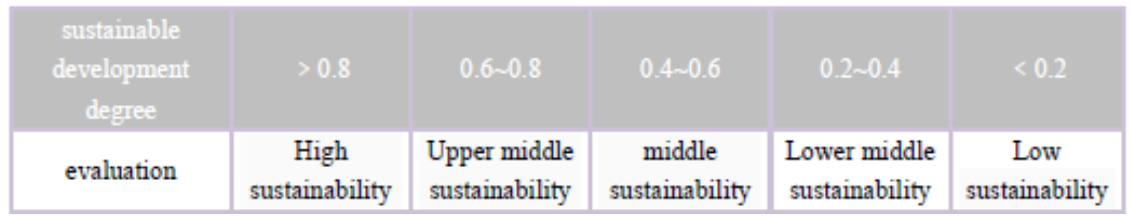

Therefore we can safely come to the conclusion that America and Canada are being in the level of Upper middle sustainability; China being in middle sustainability level while Sudan and Haiti being in Lower middle sustainability level.

\subsection{Model application}

\subsubsection{For when and how a county is sustainable or unsustainable}

When we employ the improved model to the problem, we manage to obtain each year's sustainability scores for Haiti. From the chart below we can easily find that the scores for 2010 is quiet low, accounting for the destructive earthquake damaged its sustainability. Except in2011, when Haiti was in low sustainability level, Haiti's sustainability are in lower middle level. in 2011 and 2012, its sustainability come to the process of recovery and come to normal gradually.

\begin{tabular}{|c|c|c|c|c|c|c|c|c|}
\hline year & 2005 & 2006 & 2007 & 2008 & 2009 & 2010 & 2011 & 2012 \\
\hline scores & 0.2657 & 0.2683 & 0.2834 & 0.2892 & 0.2933 & 0.1735 & 0.2238 & 0.2537 \\
\hline
\end{tabular}




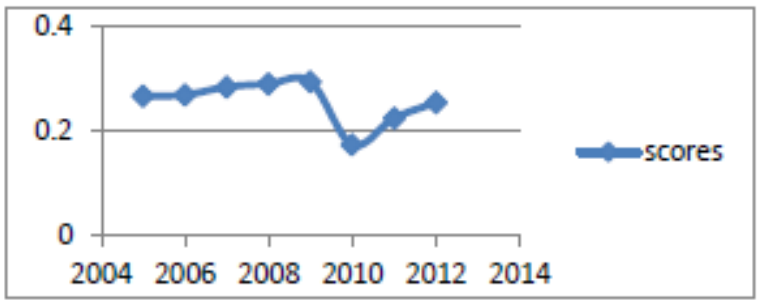

Figure 1 The scores of Haiti

2.7.2 .For countries that need the most support and intervention

According to the improved model, we obtain Scores of sustainability of the top 5 Least Developed Countries among the United Nations list of the 48 Least Developed Countries, the chart is as follows:

\begin{tabular}{|c|c|c|c|c|c|}
\hline Country & $\begin{array}{l}\text { Central } \\
\text { African } \\
\text { Republic }\end{array}$ & Malawi & Burundi & Madagascar & Niger \\
\hline $\begin{array}{c}\text { Scores of } \\
\text { sustainability }\end{array}$ & 0.1637 & 0.1783 & 0.2034 & 0.2196 & 0.2238 \\
\hline
\end{tabular}

From the chart ,we can come to the conclusion that the sustainability levels of the 5 Least Developed Countries is quiet low ,therefore the needed aids and interventions are essential in these 5 Least Developed Countries.

\section{Acknowledgments}

This work was financially supported by Kaite Li.

\section{References}

[1] http://en.wikipedia.org/wiki/Time_series

[2]http://baike.baidu.com/link?url=ZRReNfXHC_1GDu_NoMCAUtav5MW94E-OMMRG-gkaAd 2FUKJT-G18lKPEkNVJnMXy4BdMZ4YibB34ZBKgxKiQ2q

[3] World Bank Data (http://data.worldbank.org)

[4]Brundtland Commission(1987)." Report of the World Commission on Environment and Development". United Nations.

[5] Barron F H, Barrett B E. Decision quality using ranked attribute weights[J]. Management Science, 1996, 42(11): 1515-1523.

[6] National data http: // data .stats .gov .cn /workspace /index ?a = q\&type =global \& dbcode =gjnd $\& m=$ gjnd $\&$ dimension=zb\&code=A0101\&region=213\&time=2012,2012

[7] http://en.wikipedia.org/wiki/Analytic_hierarchy_process

[8] http://en.wikipedia.org/wiki/Decision_matrix

[9] http://www.cnki.com.cn/Article/CJFDTotal-HJKZ200303029.htm

[10]http://wenku.baidu.com/link?url=o6c1kezk7gVZI4p2F7uaS6z-ofIEr9X5Aa3SvOHeMMhLCq Mgr 